\title{
Determinants of health-related quality of life proxy rating disagreement between caregivers of children with cancer
}

\author{
Niki Rensen ${ }^{1,2}$ - Lindsay M. H. Steur ${ }^{1,2}$. Sasja A. Schepers 2,3 - Johannes H. M. Merks ${ }^{2,4}$. Annette C. Moll ${ }^{5}$ (1) \\ Gertjan J. L. Kaspers ${ }^{1,2}$ - Raphaële R. L. Van Litsenburg ${ }^{1,2} \oplus$ - Martha A. Grootenhuis ${ }^{2,3}$
}

Accepted: 8 November 2019 / Published online: 9 December 2019

(c) The Author(s) 2019

\begin{abstract}
Purpose Proxy reports of health-related quality of life (HRQoL) are commonly used in pediatric oncology. However, it is not known if caregivers' reports differ. This study therefore aims to compare paternal and maternal proxy reports, and explore determinants of couple disagreement (sociodemographic and medical characteristics, and parental QoL and distress).

Methods Both parents completed the PedsQL generic (child's HRQoL), Short Form-12 (own QoL) and Distress Thermometer for Parents. To assess agreement in child HRQoL, intra-class correlation coefficients (ICCs) were calculated. Differences between fathers/mothers were assessed with paired $t$ tests. Systematic disagreement patterns were visualized with Bland-Altman plots. Characteristics of parental couples with a mean proxy difference in the highest quartile (highest proxy score minus lowest proxy score) were explored with multiple logistic regression analysis.

Results Parents of 120 children with cancer (87\% post-treatment, mean age $11.0 \pm 5.7$ years) participated. No significant differences were found between paternal and maternal proxy scores, and agreement was good on all scales (ICCs $0.65-0.83$ ). Bland-Altman plots revealed no systematic disagreement patterns, but there was a wide range in magnitude of the differences, and differences went in both directions. Couples with a mean proxy difference (irrespective of which direction) in the highest quartile ( \pm 20 points) were more likely to have a child in active treatment, with retinoblastoma or relapsed disease, and to diverge in their own QoL.

Conclusions If proxy reports of only one parent are available, clinicians may reasonably assume that paternal and maternal reports are interchangeable. However, if in doubt, respondent's sex is not of major importance, but clinicians should be aware of patient's and family's characteristics.
\end{abstract}

Keywords Patient-reported outcomes · Proxy reports · Quality of life · Parents · Child · Cancer · Oncology

Raphaële R. L. Van Litsenburg

R.R.L.vanLitsenburg@ prinsesmaximacentrum.nl

1 Pediatric Oncology, Emma Children's Hospital, Amsterdam UMC, Cancer Center Amsterdam, Vrije Universiteit, Amsterdam, The Netherlands

2 Princess Máxima Center for Pediatric Oncology, Utrecht, The Netherlands

3 Psychosocial Department, Emma Children's Hospital, Amsterdam UMC, University of Amsterdam, Amsterdam, The Netherlands

4 Pediatric Oncology, Emma Children's Hospital, Amsterdam UMC, University of Amsterdam, Amsterdam, The Netherlands

5 Department of Ophthalmology, Amsterdam UMC, Cancer Center Amsterdam, Vrije Universiteit, Amsterdam, The Netherlands

\section{Introduction}

Parent proxy reports are commonly used in pediatric care and research [1]. Although differences between child and parent proxy reports are clearly present when both are available [2-5], proxy reports are important for several reasons. Most importantly, proxy reports are indispensable when children are neurocognitively impaired, too young, or too ill to respond for themselves $[6,7]$. This is often true in childhood cancer. As a result of improvements in treatment and survival, patient-reported outcomes (PROs) such as healthrelated quality of life (HRQoL) are becoming increasingly important in this field. Extensive research has shown that children are at risk for HRQoL impairment, both during and after treatment. This is reported by children as well as their 
parents, although children tend to be more positive about their own functioning $[4,8-11]$.

In clinical practice and studies where parent proxy respondents are used, it is customary to ask just one parent to report on the child, most often the mother [8,9]. However, it is not well known if there are systematic differences between caregivers in their proxy HRQoL ratings [3, 4]. A large study in parents of healthy Iranian children concluded that paternal and maternal proxy HRQoL reports were interchangeable, although there were small but statistically significant differences between parents [12]. However, this is only one study. Furthermore, results in parents of healthy children may not be directly applicable to ill children, since circumstances are different and parents of ill children face additional distressing challenges $[13,14]$.

Factors that are known to influence parent proxy ratings in (chronically) ill children are among others child's age and sex, parental educational level and cultural background, and the parent's own health, QoL and distress [3, 4, 15-19]. It is not known, however, to what extent these factors play a role in disagreement in parent proxy ratings between mothers and fathers of (chronically) ill children. Since previous research in parents of children with cancer has shown that, within one family, mothers' self-reported QoL is lower than fathers', we hypothesize that mothers report lower HRQoL for their child as well [14]. Moreover, medical factors such as the child's treatment status, time since diagnosis and type of diagnosis might be of influence on proxy ratings, since these factors entail different stressors [19].

It is important to explore potential disagreement in proxy ratings between caregivers, because the presence of these differences could influence the interpretation of parentreported outcomes in pediatrics. Additionally, it is important to identify which parental couples are more likely to diverge in their proxy scores, in order to better understand in which situations more caution is warranted regarding the interpretation of these outcomes.

This study therefore primarily aims to compare paternal and maternal proxy reports of children's HRQoL in a large cohort of current and former pediatric cancer patients (hereafter referred to as children with cancer). Second, this study aims to explore possible determinants of couple disagreement in this population (e.g. sociodemographic and medical characteristics, and parents' own reported QoL and distress).

\section{Methods}

\section{Study population}

Data of this study are derived from the "Amsterdam Parent Project", a cross-sectional multicenter study on parental sleep, QoL and psychosocial functioning in childhood cancer. A detailed description of the Amsterdam Parent Project is given elsewhere [14]. For the purposes of the current study, the questionnaires on parent-rated child HRQoL as well as those on parental QoL and distress were included. In the Amsterdam Parent Project, both parents were invited through mail to complete validated questionnaires independently from each other, either on paper or through an online assessment. If parents were not living at the same address, the parent that received the invitation was asked to transfer it to the other parent. Inclusion criteria were having a child diagnosed with cancer or any type of brain tumor between January 2010 and January 2015 in the Emma Children's Hospital, Amsterdam University Medical Centers (location VUmc or AMC) and receiving follow-up care in one of these centers at time of study. Parents of deceased children or children receiving palliative care were excluded, as well as parents who were insufficiently fluent in Dutch to complete questionnaires independently.

Ultimately, 352 parents (202 mothers and 150 fathers, response rate $48 \%$ ) were included, comprising 121 parental couples. One couple was excluded from the current study because they had a child younger than 2 years of age and therefore could not complete the proxy HRQoL questionnaire (see below). The data of the remaining 120 couples are reported here.

\section{Measures}

\section{Sociodemographic and medical variables}

The following sociodemographic characteristics were assessed with a general survey: parental age and sex; highest attained educational level (according to Statistics Netherlands [20]; dichotomized for analysis as low-middle vs high); and country of birth (The Netherlands vs other). Moreover, the following child variables were extracted from the children's medical files: age and sex; diagnosis type (hematologic malignancy, brain tumor, solid tumor, retinoblastoma); cumulative treatment, defined as low risk (no intervention, surgery only, local therapy other than radiation), middle risk (chemotherapy with or without surgery) or high risk (any combination with radiation and/or stem cell transplant); relapse or second tumor (yes or no); time since diagnosis; and active treatment at time of study (yes or no).

\section{Child HRQoL}

In parents of children aged two years and over, child HRQoL was assessed with the parent proxy version of the Pediatric Quality of Life InventoryTM (PedsQL) 4.0 Generic Core Scales (2-18 years) [21]. The PedsQL consists of 23-items, addressing four domains: physical, emotional, social and school functioning. The sum of the scale scores is used to 
calculate a mean total score. Moreover, two summary scores can be calculated: the Physical Health summary score ( 8 items) and the Psychosocial Health Summary Score (PSHS, 15 items) [22]. Scores range from zero to 100 and higher scores indicate better HRQoL. Missing values were handled according to the scoring guidelines, which means that scale scores were calculated by imputing the mean of the completed items in that scale, if at least $50 \%$ of the scale items were completed [21]. The Dutch version of the PedsQL 4.0 Generic Core Scales has adequate psychometric properties. Norm values collected by Varni et al. (proxy reports 2-18 years) are available [21]. Cronbach's alpha in the study population ranged from 0.71 (social domain score) to 0.92 (physical domain and total score).

\section{Parental QoL}

Parental QoL was assessed with the Short Form-12 (SF12), a generic QoL instrument for adults [23]. It measures functional health and well-being by means of two summary scores: the Physical Component Summary score (PCS) and Mental Component Summary score (MCS). The MCS and PCS are norm-based standardized summary scores with a mean of 50 and standard deviation (SD) of 10 in the general US population [23]. Higher scores indicate better QoL. Missing values were not imputed. The Dutch version has adequate validity and reliability and Dutch norm values are available [24].

\section{Parental distress}

To measure parental distress, the thermometer score of the Distress Thermometer for Parents (DT-P) was used. Parents were asked to rate their overall distress from 0 to 10 , with a score of 4 or higher indicating clinical distress levels. This cut-off has been previously validated in parents of healthy and chronically ill children [25, 26].

\section{Statistical analysis}

\section{Study population}

Differences in child's demographic and medical characteristics between the 120 children in the current study and the other children of the Amsterdam Parent Project $(n=111)$ plus non-responders $(n=247)$ were calculated by using independent $t$ tests for continuous variables and Chi square tests for dichotomous and categorical variables.
Description of proxy-reported child HRQoL, parental QoL and distress

For the description of proxy-rated child HRQoL and parent's own QoL, means and SD were calculated for each scale, separately for fathers and mothers. Mean proxy scores of fathers and mothers of children with cancer were compared to proxy scores of parents of healthy children [21] using one-sided $t$ tests. Fathers' and mothers' own QoL and distress scores were compared with paired $t$ tests. For both differences with parents of healthy children and difference between fathers and mothers, significance level was set at $p<0.008$ after adjusting for multiple testing (Bonferroni, 0.05/6).

Relationships between parental proxy scores and own QoL and distress were assessed with Pearson's correlations, separately for fathers and mothers. Correlations between 0.2 and 0.5 were considered small, $0.5-0.8$ moderate, and $\geq 0.8$ strong.

\section{Agreement in paternal and maternal proxy HRQoL scores}

To assess agreement in paternal and maternal proxy scores, intra-class correlation coefficients (ICCs) with confidence intervals were calculated. A two-way mixed effects model was used (single measures, absolute agreement) [27]. ICCs of $<0.40$ were considered poor, $0.40-0.60$ fair, $0.60-0.80$ good and $\geq 0.80$ excellent.

Additionally, the mean differences between paternal and maternal scores were analyzed with paired $t$ tests. The meaning of the differences was displayed as effect sizes, Cohen's $d$ (mean $(a)$ - mean $(b)$, divided by the pooled SD of both groups). Effect sizes of 0.2-0.5 were considered small, $0.5-0.8$ moderate and $\geq 0.8$ large [28].

Finally, Bland-Altman plots were constructed for each scale to reveal any systematic patterns in disagreement between parents [29]. With this technique, for each couple, the mean of the father's and mother's score is plotted on the $x$-axis against the mean difference between the both parents (father's score minus mother's score) on the $y$-axis. Additionally, a horizontal reference line is added at the mean difference between fathers and mothers of the entire sample, and limits of agreements are added as horizontal reference lines at \pm 2 SD of this mean difference. Ideally, the mean difference line intersects zero at the $y$-axis, and all couples' observations are around this line.

\section{Determinants of caregiver disagreement}

For each outcome, multiple logistic regression models were built to assess predictors of a mean proxy difference in the highest quartile (p75-100) compared to the lowest three quartiles (p0-75). For this purpose, quartile groups were created of the overall mean proxy difference, irrespective of the 
direction of this difference (i.e. highest proxy score minus the lowest proxy score in each couple, instead of father's score minus mother's score). This was done because the Bland-Altman plots did not show systematic patterns in the differences, but yet a wide range in the magnitude of the differences, and differences went in both directions (equally in favor of fathers and mothers).

The above-mentioned child (medical) variables were assessed. Furthermore, the following characteristics of parental couples were assessed: difference in parental mental QoL (MCS, highest score minus lowest score), discrepancy in parental distress score (one parent with and the other parent without clinical distress; yes or no), difference in educational level (yes or no), difference in cultural background (yes or no).

A backward regression with preselection was performed. First, the relationship of all variables with the outcome were univariately tested. Variables with a statistically significant relationship, defined as $p$ value $<0.15$, were retained. Second, these variables were tested in a multiple model and only variables significantly associated with the outcome ( $p$ value set at $<0.10$ ) were retained in the final model. Effects were displayed as odds ratios (OR) with $95 \%$ confidence intervals.

All analyses were done with IBM SPSS Statistics version 22.0 and if not otherwisely specified above, a two-sided $p$ value of 0.05 was considered as statistically significant.

\section{Results}

\section{Study population}

The 120 parental couples in this study consisted of 120 mothers and 120 fathers; there were no same-sex couples. Three respondents were step parents (two stepfathers and one stepmother). Mean parental age was $43.6( \pm 7.6)$ years (45.1 ( \pm 7.6$)$ in fathers and $42.2( \pm 7.4)$ in mothers). Their children $(n=120)$ were on average $3.3( \pm 1.4)$ years from diagnosis and the majority (87\%) had finished treatment. No significant differences were found in child characteristics between participants of the study and other children of the Amsterdam Parent Project plus non-responders, except for the percentage of children in active treatment $13 \%$ in participants vs $7 \%, p=0.04$; data not shown). Parent and child characteristics are summarized in Table 1.

\section{Description of proxy-reported child HRQoL, parental QoL and distress}

Compared to proxy reports of healthy children, fathers and mothers of children with cancer both reported significantly lower child HRQoL on all domains (Table 2).
Parent's own QoL scores were available from 110 couples. Mothers reported lower mental QoL (MCS) scores than fathers (mean difference $3.9 \pm 12.2, p=0.001$ ), but similar physical QoL (PCS) scores (Table 1). Additionally, mothers reported higher distress than fathers, although their average distress levels were not in the clinical range (mean thermometer score 3.4 vs $2.6, p=0.005$ ).

Table 3 shows the correlations between proxy-rated child HRQoL and parental QoL. In both fathers and mothers, small to moderate positive correlations $( \pm 0.5)$ were found between parental MCS and parent-rated child's total HRQoL score and psychosocial score (PSHS). Additionally, there was a moderate correlation between MCS in fathers and child's emotional functioning. Correlations between parental MCS and other child domains were small (0.3-0.4). There were no significant correlations between maternal PCS and parent-rated child HRQoL. In fathers, own physical QoL (PCS) had a significant small correlation $(0.3)$ with parentrated child's emotional functioning. Regarding distress, for both mothers and fathers, significant moderate negative correlations (0.4-0.6) were found between parental distress and all proxy scales.

\section{Agreement in paternal and maternal proxy HRQoL scores}

Table 2 summarizes parental agreement on different Ped$\mathrm{sQL}$ subscales. Differences in proxy ratings between fathers and mothers were not significant and effect sizes were small (0.03-0.10). Intra-class correlation coefficients were good on the PSHS, social functioning and school functioning scales, and excellent on the physical functioning, emotional functioning and total HRQoL scales.

Bland-Altman plots (Fig. 1) did not reveal any systematic patterns in disagreement, but there was a very wide range in the magnitude of differences (up to 50 points in some couples). These differences went in both directions; i.e. both higher ratings by fathers compared to mothers and vice versa.

\section{Determinants of caregiver disagreement}

Table 4 shows the quartiles of the proxy difference irrespective of the direction, with corresponding means. The mean difference in the highest quartile ranged from 18.6 (total HRQoL) to 29.9 points (school functioning). Univariate regression models are displayed in Table 5 , and the final multiple regression models in Table 6. For the total score and PSHS score, couples with the largest difference were more likely to have a child in active treatment (OR 3.1 [0.8-11.2], $p=0.091$, and OR 4.2 [1.2-15.2], $p=0.030$, respectively). For the physical functioning and school functioning score, 
Table 1 Parent $(n=240)$ and child $(n=120)$ characteristics

\begin{tabular}{|c|c|c|}
\hline & \multicolumn{2}{|l|}{ Parents } \\
\hline & Mothers & Fathers \\
\hline \multicolumn{3}{|l|}{ Relationship to child } \\
\hline Parent & 119 & 118 \\
\hline Stepparent & 1 & 2 \\
\hline Mean age (SD) & $42.2(7.4)$ & $45.1(7.6)$ \\
\hline \multicolumn{3}{|l|}{ Marital status (\%) } \\
\hline Married/living together & $113(94.2)$ & $114(95.0)$ \\
\hline Single/divorced/widowed & $7(5.8)$ & $6(5.0)$ \\
\hline \multicolumn{3}{|l|}{ Country of birth (\%) } \\
\hline The Netherlands & $112(93.3)$ & $110(91.7)$ \\
\hline Other & $8(6.7)$ & $10(8.3)$ \\
\hline \multicolumn{3}{|l|}{ Educational level $^{\mathrm{a}}(\%)$} \\
\hline Low & $11(9.2)$ & $13(10.8)$ \\
\hline Middle & $61(50.8)$ & $49(40.8)$ \\
\hline High & $44(36.7)$ & $54(45.0)$ \\
\hline Other & $1(0.8)$ & $0(0.0)$ \\
\hline Unknown & $3(2.5)$ & $4(3.3)$ \\
\hline \multicolumn{3}{|l|}{ Self-reported chronic illness (\%) } \\
\hline Yes & $32(26.7)$ & $15(12.5)$ \\
\hline No & $85(70.8)$ & $99(82.5)$ \\
\hline Unknown & $3(2.5)$ & $6(5.0)$ \\
\hline Mean SF-12 Mental Component Summary score (SD) & $46.3(12.3)$ & $50.2(9.5)^{*}$ \\
\hline Mean SF-12 Physical Component Summary score (SD) & $52.7(7.6)$ & $52.8(7.3)$ \\
\hline Mean distress thermometer score (SD) & $3.4(2.8)$ & $2.6(2.6)^{*}$ \\
\hline \multicolumn{3}{|l|}{ Children } \\
\hline \multicolumn{3}{|l|}{ Child's sex (\%) } \\
\hline Male & & $60(50.0)$ \\
\hline Female & & $60(50.0)$ \\
\hline \multicolumn{3}{|l|}{ Diagnosis $(\%)$} \\
\hline Hematologic malignancy & & $42(35.0)$ \\
\hline Brain tumor & & $28(23.3)$ \\
\hline Solid tumor & & $42(35.0)$ \\
\hline Retinoblastoma & & $8(6.7)$ \\
\hline \multicolumn{3}{|l|}{ Relapse/second tumor (\%) } \\
\hline Yes & & $13(10.8)$ \\
\hline No & & $107(89.2)$ \\
\hline Mean child age at study in years (SD) & & $11.0(5.7)$ \\
\hline Mean time since diagnosis in months (SD) & & $39.4(17.2)$ \\
\hline \multicolumn{3}{|l|}{ Cumulative treatment ${ }^{\mathrm{b}}(\%)$} \\
\hline Low risk & & $26(21.7)$ \\
\hline Middle risk & & $53(44.2)$ \\
\hline High risk & & $41(34.2)$ \\
\hline \multicolumn{3}{|l|}{ Active treatment at time of study (\%) } \\
\hline Yes & & $16(13.3)$ \\
\hline No & & $104(86.7)$ \\
\hline
\end{tabular}

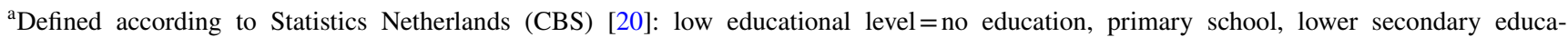
tion; middle educational level = upper secondary education, preuniversity education, and intermediate vocational education; high educational level = higher vocational education, university. Other: foreign education

${ }^{\mathrm{b}}$ Low risk therapy $=$ no intervention, surgery only, local therapy other than radiation; middle risk therapy= chemotherapy with or without surgery; high risk therapy $=$ any combination with radiation and/or stem cell transplant

$* p<0.05$, indicating a significant difference between fathers and mothers 
Table 2 Proxy HRQoL ratings of mothers and fathers of children with cancer: differences with healthy children and level of parental agreement

\begin{tabular}{|c|c|c|c|c|c|c|}
\hline \multirow[t]{2}{*}{$\begin{array}{l}\text { Proxy-rated HRQoL } \\
\text { scale }\end{array}$} & $\begin{array}{l}\text { Parents of healthy } \\
\text { children }(n=618-711) \\
{[21]}\end{array}$ & $\begin{array}{l}\text { Fathers of chil- } \\
\text { dren with cancer } \\
(n=95-113)\end{array}$ & $\begin{array}{l}\text { Mothers of chil- } \\
\text { dren with cancer } \\
(n=95-113)\end{array}$ & $\begin{array}{l}\text { Parental agreement } \\
\text { (oncology sample) }\end{array}$ & \multirow[t]{2}{*}{$\begin{array}{l}\text { Mean difference } \\
\text { father-mother } \\
\text { (SD) }\end{array}$} & \multirow[t]{2}{*}{ ES } \\
\hline & Mean (SD) & Mean (SD) & Mean (SD) & $\mathrm{ICC}[95 \% \mathrm{CI}]$ & & \\
\hline Total HRQoL & $87.6(12.3)$ & $80.1(17.6)^{*}$ & $79.1(18.0)^{*}$ & $0.83 *[0.76,0.88]$ & $0.97(10.4)$ & 0.05 \\
\hline PSHS & $86.6(12.8)$ & $79.2(17.2)^{*}$ & $77.6(17.8)^{*}$ & $0.78 *[0.68,0.85]$ & $1.66(11.7)$ & 0.09 \\
\hline Physical functioning & $89.3(16.4)$ & $80.9(22.3)^{*}$ & $81.6(22.2)^{*}$ & $0.83^{*}[0.76,0.88]$ & $-0.68(13.0)$ & 0.03 \\
\hline Emotional functioning & $82.6(17.5)$ & $74.4(22.3)^{*}$ & $72.1(21.9)^{*}$ & $0.80 *[0.71,0.86]$ & $2.28(14.0)$ & 0.10 \\
\hline Social functioning & $91.6(14.2)$ & $82.0(18.6)^{*}$ & $80.4(20.1)^{*}$ & $0.65 *[0.53,0.74]$ & $1.64(16.3)$ & 0.08 \\
\hline School functioning & $85.5(17.6)$ & $79.9(20.2)^{*}$ & $78.0(21.6)^{*}$ & $0.67 *[0.54,0.76]$ & $1.95(17.1)$ & 0.09 \\
\hline
\end{tabular}

PSHS Psychosocial Health Summary Score, ES effect size (Cohen's $d$ )

${ }^{*} p<0.001$; indicating a significant difference with parents of healthy children

Table 3 Correlations between maternal and paternal proxy HRQoL ratings and own QoL and distress

\begin{tabular}{llclllc}
\hline Proxy-rated HRQoL scale & MCS mothers & PCS mothers & MCS fathers & PCS fathers & Distress mothers & Distress fathers \\
\hline Total HRQoL & $0.47^{*}$ & -0.01 & $0.47^{*}$ & 0.18 & $-0.53^{*}$ & $-0.54^{*}$ \\
PSHS & $0.46^{*}$ & 0.04 & $0.47^{*}$ & 0.19 & $-0.52^{*}$ & $-0.56^{*}$ \\
Physical functioning & $0.38^{*}$ & -0.03 & $0.38^{*}$ & 0.14 & $-0.46^{*}$ & $-0.43^{*}$ \\
Emotional functioning & $0.35^{*}$ & 0.12 & $0.50^{*}$ & $0.26^{*}$ & $-0.44^{*}$ & $-0.61^{*}$ \\
Social functioning & $0.31^{*}$ & 0.11 & $0.41^{*}$ & 0.13 & $-0.42^{*}$ & $-0.37^{*}$ \\
School functioning & $0.42^{*}$ & -0.05 & $0.31^{*}$ & 0.07 & $-0.39^{*}$ & $-0.40^{*}$ \\
\hline
\end{tabular}

PSHS Psychosocial Health Summary Score, MCS Mental Component Summary score, PCS Physical Component Summary score

${ }^{*} p<0.001$

couples were more likely to diverge in their mental QoL (OR 1.1 [1.0-1.1], $p=0.023$, and OR 1.1 [1.0-1.1], $p=0.06$, respectively). For the emotional functioning score, couples were more likely to diverge when they had a child with retinoblastoma (OR 9.1 [1.5-54.9], $p=0.02$ ) or a child with a relapse or second tumor (OR 6.5 [1.8-22.9], $p=0.004)$.

\section{Discussion}

\section{Main findings and implications}

The aims of this study were to assess potential differences in proxy HRQoL ratings between fathers and mothers of children with cancer, and to explore determinants of caregiver disagreement. On average, we found good agreement in paternal and maternal proxy ratings, and no significant differences between parents. This implies that if only one report is available, clinicians and researchers can reasonably assume that, in general, paternal and maternal proxy HRQoL ratings of their child with cancer are interchangeable. However, when comparing the highest rating parent to the lowest rating parent (instead of concentrating on the difference between fathers and mothers), proxy reports in the highest quartile differed on average 20 points. This means that approximately $25 \%$ of parents report quite differently about their child's HRQoL. These couples were more likely to have a child in active treatment or with a relapse, have a child with retinoblastoma, and to diverge in their own mental QoL-compared to the parental couples with a proxy difference in the lower three quartiles (a difference between 0 and 10 points on most scales). Yet for some scales (e.g. social functioning) we could not specify determinants of this discrepancy.

This study adds important information regarding the interpretation of parent-reported outcomes in pediatric oncology.

Previous research in healthy children showed that paternal and maternal proxy HRQoL reports were interchangeable [12]. Moreover, in a sample of adolescent burn survivors as well as in children and adolescents in outpatient psychotherapy treatment, moderate to high agreement was found in proxy HRQoL reports of parent-dyads [30, 31]. However, to our knowledge, no previous studies have been performed on this subject in pediatric oncology. Furthermore, previous studies only focused on differences in paternal and maternal reports, and perhaps overlooked differences that would have been found if they had compared the highest and lowest 

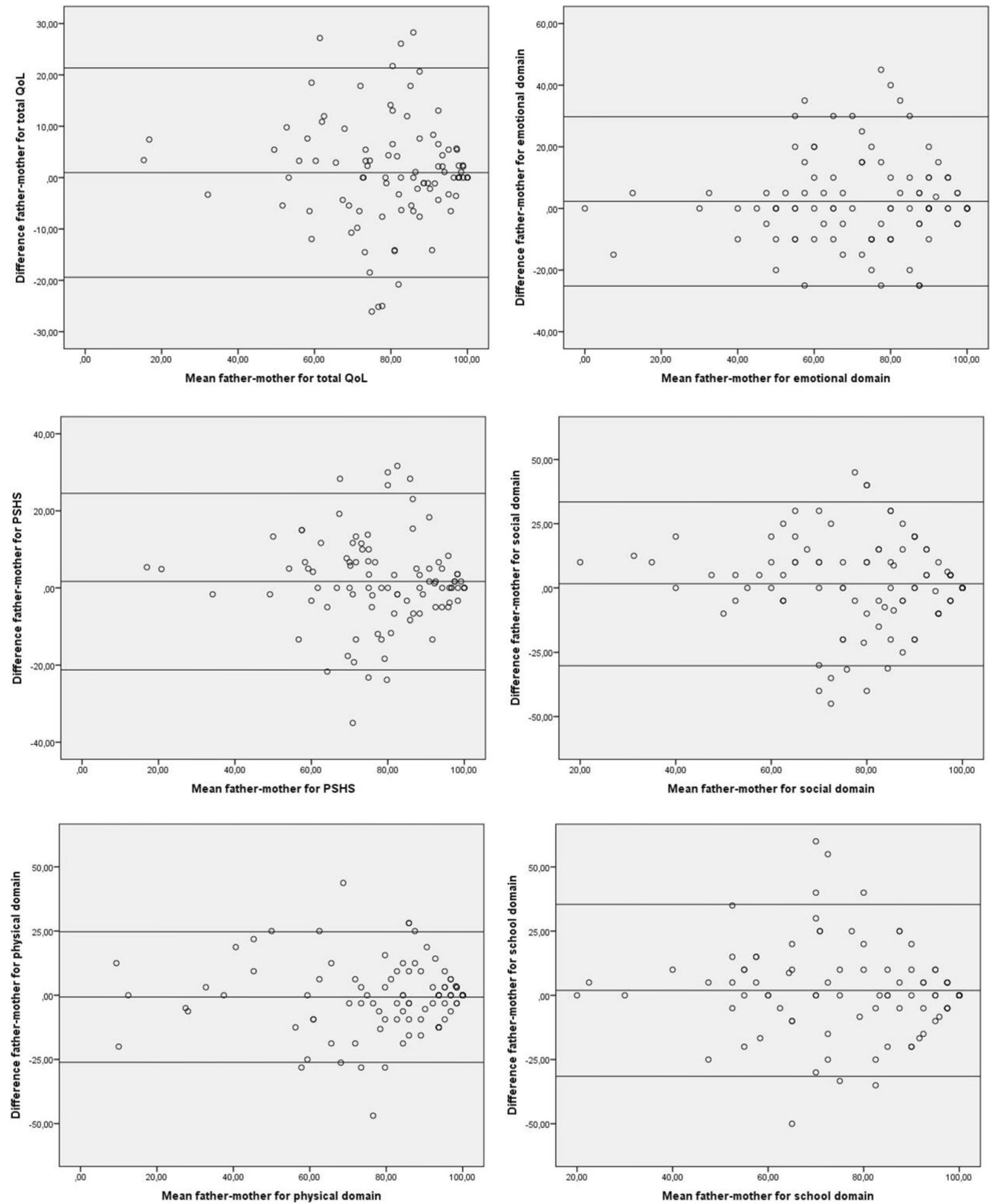

Fig. 1 Bland-Altman plots for each proxy HRQoL scale, indicating patterns of disagreement between fathers and mothers. Explanation of the plots: the mean of the father's and mother's score is plotted on the $x$-axis against the mean difference betweenthe both parents (father's

score minus mother's score) on the $y$-axis. Additionally, the horizontal reference line closest to zeroindicates the mean difference between fathers and mothers of the entire sample, and limits of agreements are added as horizontalreference lines at $\pm 2 \mathrm{SD}$ of this mean difference 
Table 4 Quartiles of proxy differences (highest minus lowest score) and corresponding means

\begin{tabular}{lllllll}
\hline Quartile & $\begin{array}{l}\text { Total HRQoL score } \\
\text { Mean difference }\end{array}$ & $\begin{array}{l}\text { PSHS score } \\
\text { Mean difference } \\
\text { (SD) }\end{array}$ & $\begin{array}{l}\text { Physical functioning } \\
\text { score } \\
\text { Mean difference } \\
\text { (SD) }\end{array}$ & $\begin{array}{l}\text { Emotional function- } \\
\text { ing score } \\
\text { Mean difference } \\
\text { (SD) }\end{array}$ & $\begin{array}{l}\text { Social functioning } \\
\text { score } \\
\text { Mean difference } \\
\text { (SD) }\end{array}$ & $\begin{array}{l}\text { School functioning } \\
\text { score } \\
\text { Mean difference (SD) }\end{array}$ \\
\hline p0-25 & $0.38(0.53)$ & $0.54(0.78)$ & $0.00(0.00)$ & $0.00(0.00)$ & $0.00(0.00)$ & $0.00(0.00)$ \\
p25-50 & $3.14(0.80)$ & $3.80(1.24)$ & $3.33(0.61)$ & $4.94(0.27)$ & $5.26(1.31)$ & $5.00(0.00)$ \\
p50-75 & $7.16(1.72)$ & $8.29(2.26)$ & $9.38(2.46)$ & $10.0(0.00)$ & $11.4(2.26)$ & $11.5(2.79)$ \\
p75-100 & $18.6(5.53)$ & $20.1(6.68)$ & $23.6(8.30)$ & $23.2(8.01)$ & $28.0(8.37)$ & $29.9(11.3)$ \\
\hline
\end{tabular}

PSHS Psychosocial Health Summary Score

Table 5 Univariate logistic regression models for proxy difference in the highest quartile

\begin{tabular}{|c|c|c|c|c|c|c|}
\hline & $\begin{array}{l}\text { Difference in total } \\
\text { HRQoL (p75-100) }\end{array}$ & $\begin{array}{l}\text { Difference in } \\
\text { PSHS (p75-100) }\end{array}$ & $\begin{array}{l}\text { Difference in } \\
\text { physical function- } \\
\text { ing score (p75- } \\
100)\end{array}$ & $\begin{array}{l}\text { Difference in emo- } \\
\text { tional functioning } \\
\text { score (p75-100) }\end{array}$ & $\begin{array}{l}\text { Difference in } \\
\text { social functioning } \\
\text { score (p75-100) }\end{array}$ & $\begin{array}{l}\text { Difference in school } \\
\text { functioning score } \\
\text { (p75-100) }\end{array}$ \\
\hline & OR $[95 \% \mathrm{CI}]$ & OR $[95 \% \mathrm{CI}]$ & OR $[95 \% \mathrm{CI}]$ & OR $[95 \% \mathrm{CI}]$ & OR $[95 \% \mathrm{CI}]$ & OR $[95 \% \mathrm{CI}]$ \\
\hline \multicolumn{7}{|c|}{ Child (medical) variables } \\
\hline Age & $0.94[0.85-1.03]$ & $0.97[0.89-1.06]$ & $1.02[0.94-1.10]$ & $0.98[0.91-1.06]$ & $0.99[0.92-1.07]$ & $0.98[0.90-1.07]$ \\
\hline Female sex & $0.92[0.35-2.34]$ & $1.39[0.55-3.46]$ & $0.62[0.25-1.55]$ & $0.74[0.32-1.71]$ & $1.78[0.76-4.15]$ & $0.90[0.36-2.22]$ \\
\hline $\begin{array}{l}\text { Brain tumor } \\
\text { versus hemato- } \\
\text { logic malig- } \\
\text { nancy }\end{array}$ & $0.85[0.24-3.04]$ & $1.10[0.32-3.74]$ & $0.87[0.27-2.83]$ & $0.40[0.11-1.44]$ & $1.14[0.38-3.41]$ & $0.73[0.23-2.39]$ \\
\hline $\begin{array}{l}\text { Solid tumor } \\
\text { versus hemato- } \\
\text { logic malig- } \\
\text { nancy }\end{array}$ & $0.56[0.18-1.72]$ & $0.66[0.22-1.97]$ & $0.61[0.20-1.87]$ & $0.70[0.25-1.92]$ & $0.76[0.27-2.14]$ & $0.26[0.08-0.85]^{* * *}$ \\
\hline $\begin{array}{l}\text { Retinoblas- } \\
\text { toma versus } \\
\text { hematologic } \\
\text { malignancy }\end{array}$ & $2.56[0.31-21.0]$ & $1.70[0.24-12.0]$ & $1.16[0.19-7.04]$ & $\begin{array}{c}6.27[1.09- \\
36.3]^{* * *}\end{array}$ & $1.62[0.33-8.06]$ & $1.22[0.18-8.36]$ \\
\hline $\begin{array}{l}\text { Relapse or sec- } \\
\text { ond tumor }\end{array}$ & $1.39[0.33-5.89]$ & $2.06[0.53-8.02]$ & $1.67[0.47-5.98]$ & $\begin{array}{l}4.94[1.47- \\
16.6]^{* * *}\end{array}$ & $1.27[0.36-4.46]$ & $1.33[0.32-5.57]$ \\
\hline $\begin{array}{l}\text { Time since diag- } \\
\text { nosis }\end{array}$ & $0.99[0.96-1.01]$ & $0.99[0.96-1.01]$ & $\begin{array}{l}0.97[0.94- \\
1.00]^{* * *}\end{array}$ & $1.00[0.97-1.02]$ & $0.99[0.97-1.02]$ & $1.00[0.98-1.03]$ \\
\hline Active treatment & $3.06[0.84-11.2]^{* *}$ & $\begin{array}{l}4.17[1.15- \\
15.2]^{* * *}\end{array}$ & $\begin{array}{l}3.67[1.10- \\
12.2]^{* * *}\end{array}$ & $1.64[0.49-5.46]$ & $1.00[0.30-3.44]$ & $2.43[0.70-8.49]^{* *}$ \\
\hline \multicolumn{7}{|c|}{ Parental couples' variables } \\
\hline $\begin{array}{l}\text { Difference in } \\
\text { educational } \\
\text { level }\end{array}$ & $0.77[0.29-2.01]$ & $0.56[0.21-1.49]$ & $0.63[0.24-1.66]$ & $0.85[0.36-2.03]$ & $0.70[0.29-1.65]$ & 0.87 [0.34-2.22] \\
\hline $\begin{array}{l}\text { Difference in } \\
\text { cultural back- } \\
\text { ground }\end{array}$ & - & - & $0.57[0.07-4.94]$ & $0.39[0.05-3.37]$ & $1.11[0.20-6.07]$ & - \\
\hline $\begin{array}{l}\text { Difference in } \\
\text { mental quality } \\
\text { of life (MCS) }\end{array}$ & $1.02[0.96-1.08]$ & $1.03[0.97-1.08]$ & $\begin{array}{l}1.06[1.00- \\
1.11]^{* * *}\end{array}$ & $1.00[0.95-1.05]$ & $1.01[0.97-1.06]$ & $1.05[1.00-1.11]^{* *}$ \\
\hline $\begin{array}{l}\text { Discrepancy in } \\
\text { distress level } \\
\text { (clinical/non } \\
\text { clinical) }\end{array}$ & $2.29[0.79-6.60]^{*}$ & $1.79[0.63-5.02]$ & $2.69[0.97-7.45]^{* *}$ & $1.92[0.76-4.86]$ & $1.07[0.41-2.79]$ & 1.08 [0.37-3.19] \\
\hline
\end{tabular}

PSHS Psychosocial Health Summary Score, MCS Mental Component Summary score

${ }^{*} p<0.15 ; * * p<0.10 ; * * * p<0.05$ 
Table 6 Final multivariable logistic regression models for proxy difference in the highest quartile

\begin{tabular}{|c|c|c|c|c|c|}
\hline & $\begin{array}{l}\text { Difference in total } \\
\text { HRQoL (p75-100) }\end{array}$ & $\begin{array}{l}\text { Difference in PSHS } \\
\text { (p75-100) }\end{array}$ & $\begin{array}{l}\text { Difference in physical } \\
\text { functioning score } \\
\text { (p75-100) }\end{array}$ & $\begin{array}{l}\text { Difference in emo- } \\
\text { tional functioning } \\
\text { score (p75-100) }\end{array}$ & $\begin{array}{l}\text { Difference in school } \\
\text { functioning score (p75- } \\
100)\end{array}$ \\
\hline & OR $[95 \% \mathrm{CI}]$ & OR $[95 \% \mathrm{CI}]$ & OR $[95 \% \mathrm{CI}]$ & OR $[95 \% \mathrm{CI}]$ & OR $[95 \% \mathrm{CI}]$ \\
\hline \multicolumn{6}{|l|}{ Child (medical) variables } \\
\hline \multicolumn{6}{|l|}{ Age } \\
\hline \multicolumn{6}{|l|}{ Female sex } \\
\hline $\begin{array}{l}\text { Brain tumor versus } \\
\text { hematologic malig- } \\
\text { nancy }\end{array}$ & & & & $0.41[0.11-1.60]$ & \\
\hline $\begin{array}{l}\text { Solid tumor versus } \\
\text { hematologic malig- } \\
\text { nancy }\end{array}$ & & & & $0.80[0.27-2.34]$ & \\
\hline $\begin{array}{l}\text { Retinoblastoma } \\
\text { versus hematologic } \\
\text { malignancy }\end{array}$ & & & & $9.14[1.5-54.9]^{* *}$ & \\
\hline $\begin{array}{l}\text { Relapse or second } \\
\text { tumor }\end{array}$ & & & & $6.49[1.84-22.9]^{* *}$ & \\
\hline \multicolumn{6}{|l|}{ Time since diagnosis } \\
\hline Active treatment & $3.06[0.84-11.2]^{*}$ & $4.17[1.15-15.2]^{* *}$ & & & \\
\hline \multicolumn{6}{|c|}{ Parental couples' variables } \\
\hline \multicolumn{6}{|l|}{$\begin{array}{l}\text { Difference in educa- } \\
\text { tional level }\end{array}$} \\
\hline \multicolumn{6}{|l|}{$\begin{array}{l}\text { Difference in cultural } \\
\text { background }\end{array}$} \\
\hline $\begin{array}{l}\text { Difference in mental } \\
\text { quality of life } \\
\text { (MCS) }\end{array}$ & & & $1.06[1.00-1.11]^{* *}$ & & $1.05[1.00-1.11]^{*}$ \\
\hline $\begin{array}{l}\text { Discrepancy in dis- } \\
\text { tress level (clinical/ } \\
\text { non clinical) }\end{array}$ & & & & & \\
\hline
\end{tabular}

PSHS Psychosocial Health Summary Score, MCS Mental Component Summary score

The Social Functioning domain is not displayed since no significant variables were retained in the final regression model

${ }^{*} p<0.10 ; * * p<0.05$

proxy ratings. Also, determinants of caregiver disagreement have not been previously studied yet.

It is known that mothers are most often the primary caregivers. Especially in pediatric illness populations, mothers report higher distress and lower QoL, factors that can both influence proxy ratings [15-17]. Also in our study population, mothers reported lower QoL and higher distress for themselves than fathers. Therefore, if parents would rate their child's HRQoL differently, we anticipated mothers to give lower ratings than fathers. This hypothesis is further strengthened by findings of previous studies in primary caregivers of healthy children, which showed that the relationship between parent's own (mental) health and their proxy ratings was specifically present in mothers, more than in fathers $[15,18]$.

However, results of our study show that differences in proxy ratings were bidirectional, and in both parents equally correlated with own distress and mental QoL.
The latter could explain why specifically the difference in mental QoL within a couple was a significant predictor of finding a large proxy HRQoL difference (for the physical functioning and school functioning scales). Furthermore, these findings might indicate that the situation of healthy children cannot be directly applied to pediatric illness populations, but future research is warranted.

We found that parents were more likely to differ in their proxy-rated total HRQoL and PSHS scores if their child was still in active treatment. This finding should be interpreted with caution, since we only had few children in our sample that were still in active treatment. Yet a previous study also found differences in agreement on and off treatment, although this study investigated child proxy agreement instead of parental agreement [19]. Especially during the child's cancer treatment the primary caregiver is likely to be more closely involved with the child than the second caregiver [32, 33]. It might be that this could 
either enhance or relieve the worries of the second parent, considering the bidirectional differences that we found in the proxy ratings, but this warrants further research.

Additionally, for the emotional functioning score, we found larger differences if parents had a child with retinoblastoma or a relapse. This might be explained by the larger uncertainty that these characteristics entail; i.e. the hereditary nature of retinoblastoma or fear of blindness, and the worse prognosis of relapsed cancer.

Based on previous studies, we would have expected that a discrepancy in distress level between parents would be a significant predictor as well $[15,16]$. However, we did not find this. An explanation might be that our sample did not have clinical distress scores on average.

With regards to sociodemographic factors, we did not find a relationship between having a proxy difference in the highest quartile and differences between parents in educational level or cultural background, although we know that these factors can influence proxy ratings [3,4]. This is probably explained by the little variance that we had in our sample regarding these variables. The majority of parents in our sample had a Dutch background and middle or high educational level, which is not representative for the entire Dutch population.

Finally, age and sex of the child did not predict a larger proxy difference in our study. Previous studies found conflicting results regarding these factors [3]. It might be that parents with a very young child diverge more in their scores, since it is more difficult to rate for example emotional functioning if a child cannot well express his feelings [4]. However, the children in our study were on average 11 years old, and we had few toddlers in our sample (i.e. 17 children under the age of 4 years).

\section{Clinical implications}

Several implications can be derived from our study. First, in some hospitals, electronic PROs are already systematically implemented in clinical practice. An example of this is the KLIK-portal in pediatric oncology [34, 35]. Before each outpatient visit-both during and after cancer treatmentparents and children from 8 years of age complete an online HRQoL assessment through this portal. A ten points decline in child's HRQoL over time is flagged as clinically relevant. Since only one parent completes the proxy report and this parent may differ at various time points, our study findings are directly important to clinical care. About $25 \%$ of the parents in our study diverged more than 10 points, especially during treatment. In this case, if the respondent across both time points would be different, a decline in child's HRQoL might reflect a proxy difference rather than a real decline. It should therefore be part of health-care providers' training in using PROs in clinical practice that caregivers might differ in their proxy reports. This could be specifically important in divorced parents. Unfortunately, we had too few divorced parents in our sample to draw any conclusions on this group.

Furthermore, an important conclusion of our study is that parent gender is not really important in the interpretation of proxy reports; if in doubt about the interpretation, clinicians should be aware of the family context (i.e. child's clinical characteristics and parents' own functioning). Future studies should further explore the characteristics of the parents with a clinically relevant difference in proxy ratings. Additionally, it would be interesting to investigate parental agreement in other pediatric illness populations.

\section{Limitations}

Our study has several limitations. First, the cross-sectional design only provides information on one specific moment in time, and the relatively low response rate might indicate some participation bias. Second, the far majority of the parent-dyads in our sample had a middle or high educational level, were born in the Netherlands, and were living together, which is not comparable to the general population. Especially in divorced parents, agreement in parents might be lower, but this should be confirmed in future research. Additionally, since there are no Dutch reference values available of the PedsQL proxy reports from 8 years of age, we used the reference values of Varni et al.; yet Dutch values might be slightly different. Furthermore, we did not have information on which parent was the primary caregiver; perhaps we would have found that this parent's rating was consequently higher or lower than the second parent's rating. However, we do not really expect this, since the mother is still the primary caregiver in the majority of the Dutch families [14]. Finally, it would have been interesting to include child self-reports as well, and to take these into account in the comparison of parental proxy ratings.

\section{Conclusions}

We found few differences between paternal and maternal proxy reports of children's HRQoL in pediatric cancer. This implicates that clinicians and researchers may reasonably assume that, in general, mothers' and fathers' reports are interchangeable. However, if possible, proxy reports of both parents should be included, since we have shown that $25 \%$ of parents differ widely in their scores. If only one report is available and there are any doubts of its interpretation, the respondent's sex is not of major importance, but clinicians should instead be aware of the patient's and family's characteristics. Attention to these results is warranted in care, and 
future research should further explore the characteristics of these parents.

Author contributions NR and LS: data curation, formal analysis, investigation, methodology, project administration, writing. SS: investigation, methodology, validation, writing (review/editing). JM and AM: conceptualization, writing (review/editing). MG and GK: conceptualization, methodology, resources, validation, writing (review/editing). RL: conceptualization, formal analysis, methodology, supervision, validation, writing.

\section{Compliance with ethical standards}

Conflict of interest The authors declare that they have no conflict of interest.

Ethical approval All procedures performed in studies involving human participants were in accordance with the ethical standards of the institutional research committee of the VU Medical Center (Ref. 2015.062) and with the 1964 Helsinki declaration and its later amendments or comparable ethical standards.

Informed consent Informed consent was obtained from all individual participants included in the study.

Open Access This article is licensed under a Creative Commons Attribution 4.0 International License, which permits use, sharing, adaptation, distribution and reproduction in any medium or format, as long as you give appropriate credit to the original author(s) and the source, provide a link to the Creative Commons licence, and indicate if changes were made. The images or other third party material in this article are included in the article's Creative Commons licence, unless indicated otherwise in a credit line to the material. If material is not included in the article's Creative Commons licence and your intended use is not permitted by statutory regulation or exceeds the permitted use, you will need to obtain permission directly from the copyright holder. To view a copy of this licence, visit http://creativecommons.org/licenses/by/4.0/.

\section{References}

1. Eiser, C., \& Morse, R. (2001). Can parents rate their child's health-related quality of life? Results of a systematic review. Quality of Life Research, 10, 347-357.

2. Cremeens, J., Eiser, C., \& Blades, M. (2006). Factors influencing agreement between child self-report and parent proxy-reports on the Pediatric Quality of Life Inventory 4.0 (PedsQL) generic core scales. Health and Quality of Life Outcomes, 4, 58. https://doi. org/10.1186/1477-7525-4-58.

3. Upton, P., Lawford, J., \& Eiser, C. (2008). Parent-child agreement across child health-related quality of life instruments: A review of the literature. Quality of Life Research, 17(6), 895-913. https ://doi.org/10.1007/s11136-008-9350-5.

4. Eiser, C., \& Varni, J. W. (2013). Health-related quality of life and symptom reporting: Similarities and differences between children and their parents. European Journal of Pediatrics, 172(10), 1299-1304. https://doi.org/10.1007/s00431-013-2049-9.

5. Sattoe, J. N., van Staa, A., Moll, H. A., \& On Your Own Feet Research, G. (2012). The proxy problem anatomized: Child-parent disagreement in health related quality of life reports of chronically ill adolescents. Health Qual Life Outcomes, 10, 10. https://doi. org/10.1186/1477-7525-10-10.

6. Varni, J. W., Limbers, C. A., \& Burwinkle, T. M. (2007). Parent proxy-report of their children's health-related quality of life: An analysis of 13,878 parents' reliability and validity across age subgroups using the PedsQL 4.0 Generic Core Scales. Health Qual Life Outcomes. https://doi.org/10.1186/1477-7525-5-2.

7. Ronen, G. M., Streiner, D. L., \& Rosenbaum, P. (2003). Healthrelated quality of life in children with epilepsy: Development and validation of self-report and parent proxy measures. Epilepsia, 44(4), 598-612.

8. Meeske, K., Katz, E. R., Palmer, S. N., Burwinkle, T., \& Varni, J. W. (2004). Parent proxy-reported health-related quality of life and fatigue in pediatric patients diagnosed with brain tumors and acute lymphoblastic leukemia. Cancer, 101(9), 2116-2125. https ://doi.org/10.1002/cncr.20609.

9. Varni, J. W., Burwinkle, T. M., Katz, E. R., Meeske, K., \& Dickinson, P. (2002). The PedsQL ${ }^{T M}$ in pediatric cancer reliability and validity of the pediatric Quality of Life Inventory ${ }^{\mathrm{TM}}$ Generic Core Scales, Multidimensional Fatigue Scale, and Cancer Module. Cancer, 94(7), 2090-2106.

10. Schulte, F., Russell, K. B., Cullen, P., Embry, L., Fay-McClymont, T., Johnston, D., et al. (2017). Systematic review and metaanalysis of health-related quality of life in pediatric CNS tumor survivors. Pediatric Blood \& Cancer. https://doi.org/10.1002/ pbc. 26442.

11. Fardell, J. E., Vetsch, J., Trahair, T., Mateos, M. K., Grootenhuis, M. A., Touyz, L. M., et al. (2017). Health-related quality of life of children on treatment for acute lymphoblastic leukemia: A systematic review. Pediatric Blood \& Cancer. https://doi.org/10.1002/ pbc. 26489.

12. Doostfatemeh, M., Ayatollahi, S. M., \& Jafari, P. (2015). Testing parent dyad interchangeability in the parent proxy-report of PedsQL 4.0: A differential item functioning analysis. Quality of Life Research, 24(8), 1939-1947. https://doi.org/10.1007/s1113 6-015-0931-9.

13. Hatzmann, J., Heymans, H. S., Ferrer-i-Carbonell, A., van Praag, B. M., \& Grootenhuis, M. A. (2008). Hidden consequences of success in pediatrics: parental health-related quality of life-results from the Care Project. Pediatrics, 122(5), e1030-1038. https:// doi.org/10.1542/peds.2008-0582.

14. Rensen, N., Steur, L. M., Schepers, S. A., Merks, J. H., Moll, A. C., Kaspers, G. J., et al. (2019). Gender-specific differences in parental health-related quality of life in childhood cancer. Pediatric Blood \& Cancer. https://doi.org/10.1002/pbc.27728.

15. Davis, E., Davies, B., Waters, E., \& Priest, N. (2008). The relationship between proxy reported health-related quality of life and parental distress: Gender differences. Child: Care, Health and Development, 34(6), 830-837. https://doi.org/10.111 $1 / \mathrm{j} .1365-2214.2008 .00866 . x$.

16. Davis, E., Mackinnon, A., \& Waters, E. (2012). Parent proxyreported quality of life for children with cerebral palsy: Is it related to parental psychosocial distress? Child: Care, Health and Development, 38(4), 553-560. https://doi.org/10.111 1/j.1365-2214.2011.01267.x.

17. Panepinto, J. A., Hoffmann, R. G., \& Pajewski, N. M. (2010). The effect of parental mental health on proxy reports of health-related quality of life in children with sickle cell disease. Pediatric Blood \& Cancer, 55(4), 714-721. https://doi.org/10.1002/pbc.22651.

18. Waters, E., Doyle, J., Wolfe, R., Wright, M., Wake, M., \& Salmon, L. (2000). Influence of parental gender and self-reported health and illness on parent-reported child health. Pediatrics, 106(6), $1422-1428$.

19. Yeh, C. H., Chang, C. W., \& Chang, P. C. (2005). Evaluating quality of life in children with cancer using children's self-reports and parent-proxy reports. Nursing Research, 54(5), 354-362. 
20. Centraal Bureau voor de Statistiek. (2016). Standaard Onderwijsindeling 2016 [Standard Educational Classification]. Accessed August 22, 2018, from https://www.cbs.nl/nl-nl/onze-diensten/ methoden/classificaties/onderwijs-en-beroepen/standaard-onder wijsindeling-soi-/standaard-onderwijsindeling-2016.

21. Varni, J. W., Seid, M., \& Kurtin, P. S. (2001). PedsQL TM 4.0: Reliability and validity of the pediatric Quality of Life Inventory ${ }^{\mathrm{TM}}$ version 4.0 generic core scales in healthy and patient populations. Medical Care, 39(8), 800-812.

22. Varni, J. W. (1998). The PedsQL Scoring Algorithm. Accessed August 21, 2018, from http://pedsql.org/score.html.

23. Ware, J. E., Kosinski, M., Turner-Bowker, D. M., \& Gandek, B. (2002). User's Manual for the SF-12v2 Health Survey with a Supplement Documenting SF-12 Health Survey. Lincoln, RI: QualityMetric Incorporated.

24. Mols, F., Pelle, A. J., \& Kupper, N. (2009). Normative data of the SF-12 health survey with validation using postmyocardial infarction patients in the Dutch population. Quality of Life Research, 18(4), 403-414. https://doi.org/10.1007/s11136-009-9455-5.

25. Haverman, L., van Oers, H. A., Limperg, P. F., Houtzager, B. A., Huisman, J., Darlington, A. S., et al. (2013). Development and validation of the distress thermometer for parents of a chronically ill child. Journal of Pediatrics, 163(4), 1140.e2-1146.e2. https:// doi.org/10.1016/j.jpeds.2013.06.011.

26. van Oers, H. A., Schepers, S. A., Grootenhuis, M. A., \& Haverman, L. (2017). Dutch normative data and psychometric properties for the Distress Thermometer for Parents. Quality of Life Research, 26(1), 177-182. https://doi.org/10.1007/s1113 6-016-1405-4.

27. McGraw, K. O., \& Wong, S. P. (1996). Forming inferences about some intraclass correlation coefficient. Psychological Methods, $1(1), 30-46$.

28. Cohen, J. (1988). Statistical power analysis for the behavioral sciences. New York: Academy Press.

29. Bland, J. M., \& Altman, D. G. (1986). Statistical methods for assessing agreement between two methods of clinical measurement. The Lancet, 1(8476), 307-310.
30. Pan, R., Egberts, M. R., Nascimento, L. C., Rossi, L. A., Vandermeulen, E., Geenen, R., et al. (2015). Health-Related Quality of Life in adolescent survivors of burns: Agreement on self-reported and mothers' and fathers' perspectives. Burns, 41(5), 1107-1113. https://doi.org/10.1016/j.burns.2014.12.011.

31. Weitkamp, K., Daniels, J., Rosenthal, S., Romer, G., \& WiegandGrefe, S. (2013). Health-related quality of life: Cross-informant agreement of father, mother, and self-report for children and adolescents in outpatient psychotherapy treatment. Child and Adolescent Mental Health, 18(2), 88-94. https://doi.org/10.111 $1 / \mathrm{j} .1475-3588.2012 .00656 . x$.

32. Chesler, M. A., \& Parry, C. (2001). Gender roles and/or styles in crisis: An integrative analysis of the experiences of fathers of children with cancer. Qualitative Health Research, 11(3), 363-384.

33. Mader, L., Roser, K., Baenziger, J., Vetsch, J., Falck Winther, J., Scheinemann, K., et al. (2018). Relationship status and quality of the partner relationship in parents of long-term childhood cancer survivors: The Swiss Childhood Cancer Survivor Study-Parents. Psycho-Oncology, 28(2), 309-316.

34. Haverman, L., Engelen, V., van Rossum, M. A., Heymans, H. S., \& Grootenhuis, M. A. (2011). Monitoring health-related quality of life in paediatric practice: Development of an innovative web-based application. BMC Pediatrics. https://doi. org/10.1186/1471-2431-11-3.

35. Schepers, S. A., Sint Nicolaas, S. M., Haverman, L., Wensing, M., Schouten van Meeteren, A. Y. N., Veening, M. A., et al. (2017). Real-world implementation of electronic patient-reported outcomes in outpatient pediatric cancer care. Psycho-Oncology, 26(7), 951-959. https://doi.org/10.1002/pon.4242.

Publisher's Note Springer Nature remains neutral with regard to jurisdictional claims in published maps and institutional affiliations. 